\title{
Grau de malignidade do mastocitoma cutâneo canino quanto à localização segundo as classificações de Patnaik et al. (1984) e Kiupel et al. (2011)*
}

\section{Degree of malignancy of the canine cutaneous mast cell tumor as for location according to the classifications of Patnaik et al. (1984) and Kiupel et al. (2011)}

\author{
Ana Letícia Daher Aprígio da Silva** Rodrigo Pereira de Queiroz*** Matias Pablo Juan Szabó**** \\ Alessandra Aparecida Medeiros ${ }^{* * *}$
}

\begin{abstract}
Resumo
Objetivou-se com o presente trabalho coletar dados epidemiológicos relacionados com o mastocitoma canino, além de verificar se há relação entre sua malignidade e localização e, por fim, comparar os métodos de classificação histopatológica segundo Patnaik et al. (1984) e segundo Kiupel et al. (2011). Informações foram coletadas de fichas clínicas de 55 cães e 60 fragmentos de pele com mastocitomas foram avaliados histologicamente. Verificou-se que a ocorrência de mastocitoma cutâneo não é influenciada pelo sexo e raça, porém cães sem raça definida e boxers são mais acometidos. Não há uma faixa etária susceptível bem definida, sendo o mastocitoma mais frequente em cães de 8 a 9 anos de idade. A região mais acometida foi a inguinal (50\%) e a cabeça, região que apresentou maior malignidade. Utilizando a classificação de Patnaik et al. (1984) houve diferença significativa entre as classificações histopatológicas de mastocitoma avaliadas por diferentes patologistas, o que não ocorreu utilizando a classificação de Kiupel et al. (2011). Pode-se dizer então que a classificação de Kiupel et al. (2011) gera menor divergência nos diagnósticos, demonstrando-se um método simples e eficaz para a avaliação histopatológica de mastocitoma.
\end{abstract}

Palavras-chave: mastócitos, cães, diagnóstico, neoplasia, epidemiologia.

\begin{abstract}
The aim of the present study is to collect epidemiological data related to the canine mastocytoma, to check if there is relation between malignancy and its location and, finally, to compare the methods of histopathological classification according to Patnaik et al. (1984) and Kiupel et al. (2011). Informations were collected from the clinical record of 55 dogs and 60 fragments of skin with a diagnosis of mast cell tumor were evaluated histologically. It was found that the occurrence of cutaneous mast cell tumors is not influenced by gender and race, but dogs without defined breed and boxers are most affected. There is not a well-defined susceptible age, but the most mast cell tumors in dogs often 8 to 9 years old. The highest affected region was inguinal (50\%) and head proved a region with higher malignancy. Using the classification Patnaik et al. (1984) there was a significant difference between the histopathological ratings mastocytoma evaluated by different pathologists, which did not occur using the classification Kiupel et al. (2011). It can be said then that the classification Kiupel et al. (2011) generates less divergence in the diagnosis, demonstrating a simple and effective method for histopathological evaluation of mastocytoma.
\end{abstract}

Keywords: mast cells, dogs, diagnosis, neoplasia, epidemiology.

\section{Introdução}

O mastocitoma cutâneo em cães representa $11 \%$ dos tumores malignos cutâneos, sendo o terceiro mais comum dentre os tumores cutâneos caninos, depois do lipoma e o adenoma (Villamil et al., 2011). Segundo De Nardi (2002), é a segunda neoplasia que mais acomete os cães, depois dos tumores de mama apenas. Outros autores citam a frequência de 20,9 a $22,4 \%$ (Souza et al., 2006, Meirelles et al., 2010) revelando mais uma vez a alta incidência desse tipo de neoplasia.
A classificação histológica é de fundamental importância para a determinação do prognóstico e para a escolha do tratamento (Goldschimidt e Hendrick, 2002). A identificação do grau de diferenciação dos mastocitomas é baseada em fatores como invasão, celularidade, morfologia da célula, índice mitótico, ou seja, parâmetros subjetivos (Simões et al., 1994a).

Segundo Patnaik et al. (1984) o mastocitoma pode ser classificado em grau I, II e III, considerando-se características de localização, diferenciação e arranjos celulares. Trata-se de uma classificação complexa que gera divergências nos diagnósticos.

${ }^{*}$ Recebido em 17 de fevereiro e aceito em 28 de setembro de 2014.

**Programa de Residência Uniprofissional em Medicina Veterinária - Patologia Animal - Faculdade de Medicina Veterinária - Universidade Federal de Uberlândia. Autor para correspondência. E-mail: ana.vete@yahoo.com.br

***Departamento de Patologia Animal da Faculdade de Medicina Veterinária da Universidade Federal de Uberlândia. Avenida Pará, 1720. Uberlândia - MG. CEP 38400-902.

****Departamento de Patologia Animal da Faculdade de Medicina Veterinária da Universidade Federal de Uberlândia. 
O comportamento biológico do mastocitoma cutâneo é imprevisível (Couto, 2006). Na maioria dos casos, o mastocitoma cutâneo bem diferenciado (grau I) apresenta baixo potencial metastático e de disseminação sistêmica. Os mastocitomas de graus II e III geralmente apresentam metástases para os linfonodos regionais e alto potencial para disseminação sistêmica e metastática.

Tumores localizados na cavidade oral, leito ungueal ou nas regiões inguinal, prepucial e perineal apresentam alta malignidade, independentemente do grau histológico (Tams e Macy, 1981; Turrel et al., 1988; Fox, 1998; Couto, 2006). Segundo Patnaik e colaboradores (1984), 95\% dos cães com mastocitoma cutâneo grau I sobrevivem mais de 1500 dias, comparados com $47 \%$ dos cães com grau II e 6\% com grau III.

$\mathrm{Na}$ classificação histológica dos mastocitomas cutâneos segundo Patnaik et al. (1984), o predomínio de mastocitoma cutâneo grau II e a falta de concordância nos diagnósticos entre outros autores (Strefezzi et al., 2003; Northrup et al., 2005; Preziosi et al., 2007; Pinczowski et al., 2008; Strefezzi et al., 2009) diminui a confiabilidade deste sistema de classificação. O alto índice mitótico necessário para classificação do mastocitoma como grau III, exclui alguns tumores com menor índice que poderiam apresentar comportamento biológico agressivo (Kiupel et al., 2011). Graças a esses fatores, pode existir uma divergência a respeito da classificação de mastocitoma cutâneo por diferentes patologistas, o que torna o sistema de classificação um tanto quanto impreciso.

A fim de tornar a graduação histológica padronizada e diminuir a possibilidade de variação em sua interpretação, Kiupel e seus colaboradores (2011) propuseram uma nova forma de graduação dos mastocitomas cutâneos. A nova classificação histopatológica proposta agrupa os mastocitomas como sendo de baixo e alto grau de malignidade. Trata-se de uma classificação relativamente recente, necessitando de estudos para se verificar sua adequação e correlação com a progressão do tumor, sobrevida, entre outros.

Objetivou-se com o trabalho coletar dados epidemiológicos de cães afetados pelo mastocitoma e compará-los com os encontrados na literatura, além de avaliar se a localização é um fator de risco para malignidade do mastocitoma e comparar as classificações de Patnaik et al. (1984) e Kiupel et al. (2011) para verificar qual apresenta maior concordância de diagnósticos entre os patologistas.

\section{Material e métodos}

Foram incluídos neste trabalho 60 amostras de pele de 55 cães atendidos no Hospital Veterinário da Universidade Federal de Uberlândia, durante o ano de 2013, com diagnóstico de mastocitoma. Houve cinco animais que tiveram mais de uma lesão, sendo que três apresentavam a lesão na mesma região e dois em regiões distintas.
As amostras de pele foram coletadas durante procedimento de exérese cirúrgica, conservadas em formol tamponado 10\% até sua fixação e processadas rotineiramente para confecção de lâminas histológicas, coradas em hematoxilina e eosina (HE) segundo Tolosa et al. (2003) (Figuras 1 e 2). Realizouse ainda coloração especial por azul de toluidina (SImões \& Schoning, 1994b) para uma melhor visualização dos grânulos citoplasmáticos dos mastócitos.

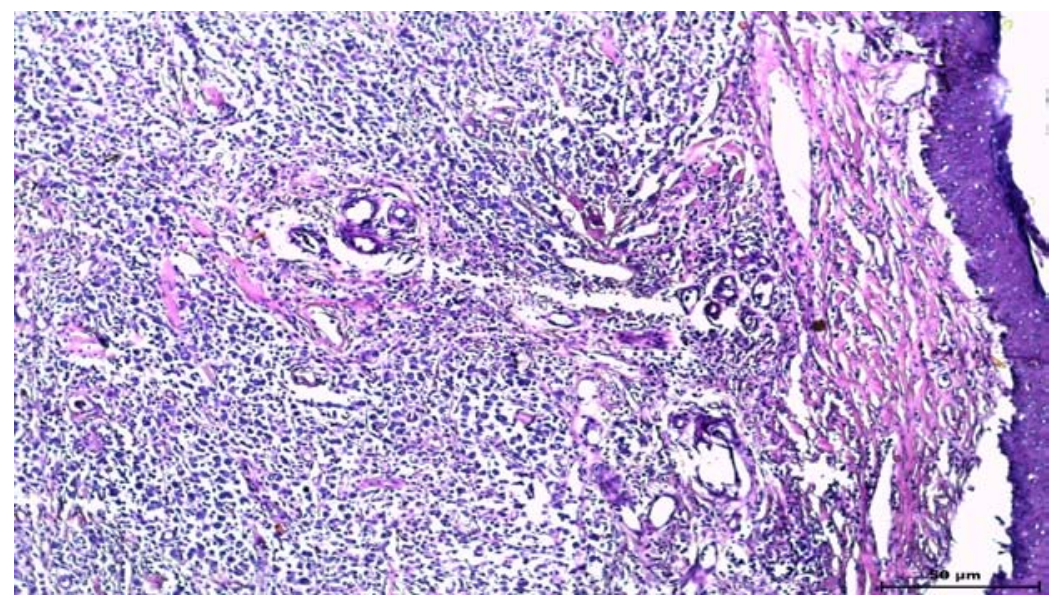

Figura 1: Fotomicrografia de mastocitoma, aumento 40X, coloração H\&E. Proliferação neoplásica de células redondas com crescimento expansivo delimitado à derme profunda e dispostas em cordões.

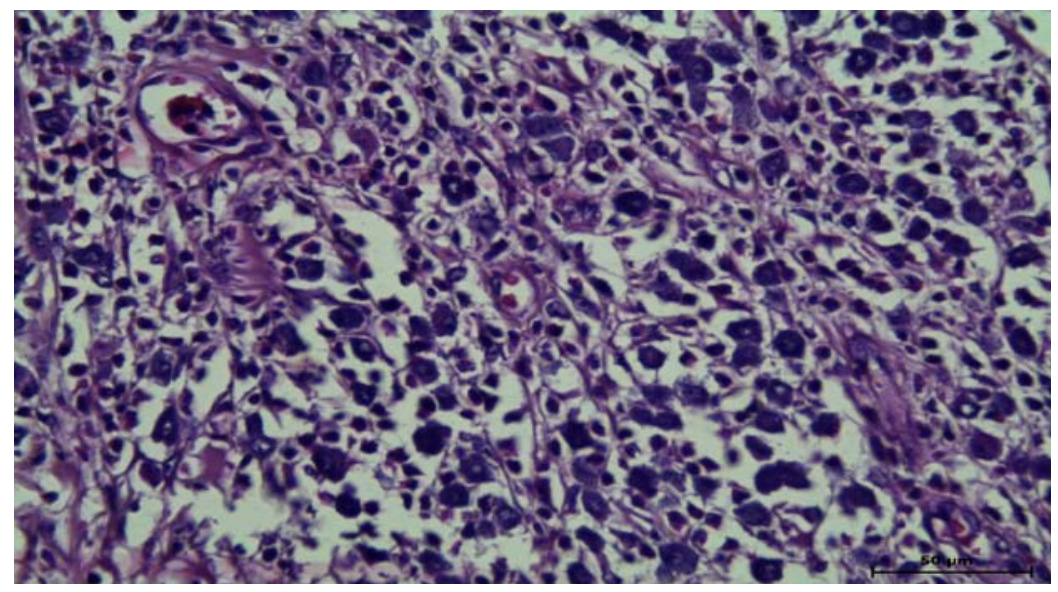

Figura 2: Fotomicrografia de mastocitoma, aumento 400X, coloração H\&E. As células caracterizam-se morfologicamente por formato arredondado, citoplasma amplo com inúmeros grânulos basofílicos e núcleo central arredondado com nucléolo único proeminente. Moderado infiltrado intersticial de eosinofílico.

Informações dos animais como: sexo, idade, raça e localização do tumor foram coletadas das fichas clínicas. Quanto à localização, as regiões anatômicas foram divididas em cabeça, membros, tronco e inguinal.

As 60 amostras foram avaliadas por três patologistas, que classificaram o mastocitoma de acordo com Patnaik et al. (1984) e Kiupel et al. (2011).

As informações dos cães com mastocitoma foram analisadas a partir de estatística descritiva e percentual. Na verificação da correlação entre sexo e ocorrência de mastocitoma, localização e grau de malignidade, segundo Kiupel et al. (2011) e verificação 
da concordância entre diagnósticos pelos dois métodos de classificação utilizou-se teste qui-quadrado com grau de significância de 10\%, realizado pelo programa Minitab 16 .

$\mathrm{Na}$ avaliação da correlação entre sexo e ocorrência do mastocitoma, entre grau de malignidade e localidade do tumor, bem como na avaliação entre os patologistas segundo a classificação de Kiupel et al. (2011), considerou-se $X_{n}^{2}=2,706$. Já na avaliação entre os patologistas segundo a classificação de Patnaik et al. (1984), utilizou-se $\mathbf{X}_{n}^{2}=4,605$, devido aos graus de liberdade.

Além do teste do qui-quadrado, a medida epidemiológica Odds Ratio também foi realizada objetivando-se saber se a localidade é um fator de risco referindo-se à malignidade do tumor, podendo assim definir quantas vezes uma neoplasia de uma determinada parte do corpo apresentou-se mais maligna que outra de localidade diferente.

O projeto de pesquisa em questão foi avaliado e aprovado pela Comissão de Ética segundo o protocolo registro CEUA/UFU 100/13

\section{Resultados e discussão}

Em relação aos dados epidemiológicos dos cães portadores de mastocitoma, $56 \%$ dos cães eram fêmeas e $44 \%$ eram machos. Bracarense et al. (2012) também obtiveram maior frequência em fêmeas (51,8\%). Em contrapartida, Rech (2003) e Patnaik et al. (1984) verificaram uma maior frequência em machos, correspondendo respectivamente a $52 \%$ e $51,8 \%$. Contudo, não houve diferença significativa quanto à ocorrência de mastocitoma com relação ao sexo $\left(\mathbf{X}^{2}=0,8909\right)$ no presente estudo, demonstrando assim que o sexo não influencia a ocorrência do tumor relatado também por outros autores (Goldschmidt e Shover, 1992; Scott et al., 2001; Rabanal e Ferrer, 2002).

A maior parte dos cães acometidos (84,44\%) apresentou idade entre cinco e doze anos (Figura 3). A média de idade dos animais utilizados neste estudo foi de 8,91 anos, sendo que Patnaik et al. (1984), Dobson e Scase (2007) e Costa-Casagrande et al. (2008) verificaram que cães adultos com idade entre 8 e 9 anos são mais acometidos por mastocitoma cutâneo.

Os cães sem raça definida $(43,33 \%)$ e da raça boxer $(20,00 \%)$ foram os mais afetados (Figura 3). Provavelmente os cães sem raça definida apresentaram maior frequência, em decorrência da casuística do Hospital Veterinário da Universidade Federal de Uberlândia. Resultados semelhantes foram obtidos por Rech (2003), que verificou maior incidência de mastocitoma em cães sem raça definida seguida da raça boxer. Em um estudo retrospectivo realizado no Hospital Veterinário da Universidade Federal do Paraná, $46,15 \%$ dos cães que apresentaram mastocitoma eram boxers (Nardi, 2002). No estudo de Torres Neto (2008), 39\% dos cães eram da raça boxer, que foi mais frequente que os cães sem raça definida.

A região inguinal (50\%) foi a mais acometida e a cabeça aquela que apresentou menor frequência de mastocitomas (10\%) (Figura 4). Segundo Daleck et al. (2009), 50\% dos mastocitomas estão confinados no tronco, região perineal, genital e inguinal, $40 \%$ nos membros e $10 \%$ na região da cabeça e pescoço.

Foram verificadas diferenças significativas apenas entre o grau de malignidade dos tumores localizados na cabeça e membros $\left(x^{2}=4,898\right)$ e inguinal e membros $\left(x^{2}=3,450\right)$, pois os tumores localizados na cabeça e na região inguinal apresentaram malignidade muito superior em relação aos localizados nos membros. Por meio da medida epidemiológica Odds Ratio, os resultados demonstraram que as neoplasias na cabeça apresentaram malignidade 3,33 vezes maior que as localizadas na região inguinal, 4,28 vezes maior que as localizadas no tórax e 13,33 vezes maior que as localizadas nos membros. Desta forma, as neoplasias localizadas na cabeça apresentaram maior grau de malignidade em relação às localizadas na região inguinal, seguida pelas localizadas no tórax e membros. Resultados semelhantes foram obtidos por outros autores (Tams e Macy, 1981; Turrel et al., 1988; Fox, 1998; Couto, 2006) que relataram alta malignidade dos tumores localizados na cavidade oral, leito ungueal ou nas regiões inguinal, prepucial e perineal, independentemente do grau histológico.

Utililzando a classificação de Patnaik et al. (1984), o patologista 1 diagnosticou $10(16,66 \%)$ tumores grau I, $34(56,66 \%)$ grau II e $16(26,68 \%)$ grau III; o patologista 2 diagnosticou $1(1,66 \%)$ tumor grau I, $40(66,66 \%)$ grau II e $19(31,68 \%)$ grau III; patologista 3 diagnosticou $9(15 \%)$ tumores grau I, $34(56,66 \%)$ grau II e $17(28,34 \%)$ grau III.

Já na classificação de Kiupel et al. (2011), os patologistas 1 e 2 diagnosticaram $33(55 \%)$ tumores de alto grau e $27(45 \%)$ de baixo grau e o patologista 3 diagnosticou $31(51,66 \%)$ tumores de alto grau e $29(48,34 \%)$ de baixo grau.

$\mathrm{Na}$ classificação de Patnaik et al. (1984) houve diferença significativa entre o patologista 1 e o patologista $2\left(X^{2}=8,107\right)$ e entre o patologista 2 e patologista $3\left(x^{2}=6,998\right)$, porém não houve diferença significativa entre o patologista 1 e o patologista $3\left(\mathbf{X}^{2}=0,083\right)$. Assim como, Strefezzi et al. (2003), Northrup et al. (2005), Preziosi et al. (2007), Pinczowski et al. (2008) e Strefezzi et al. (2009) o presente estudo verificou divergência quanto ao diagnóstico e predomínio de diagnósticos de mastocitoma grau Il quando se utiliza a classificação de Patnaik et al. (1984).

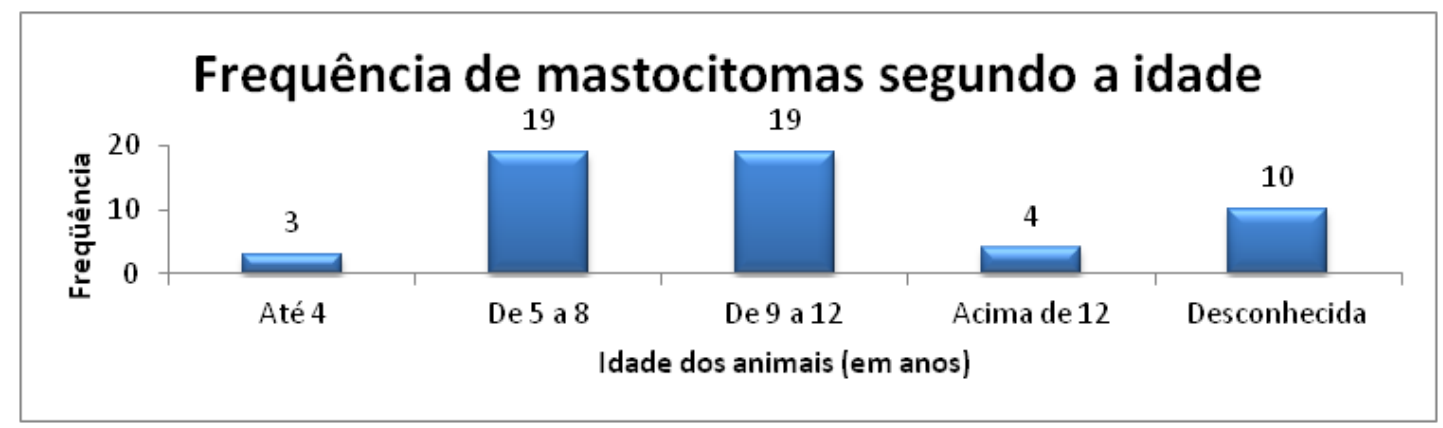

Figura 3: Frequência de mastocitomas cutâneos em cães segundo a idade, Uberlândia-MG, em 2013. 


\section{Frequência de mastocitomas de acordo com a}

\section{raça}

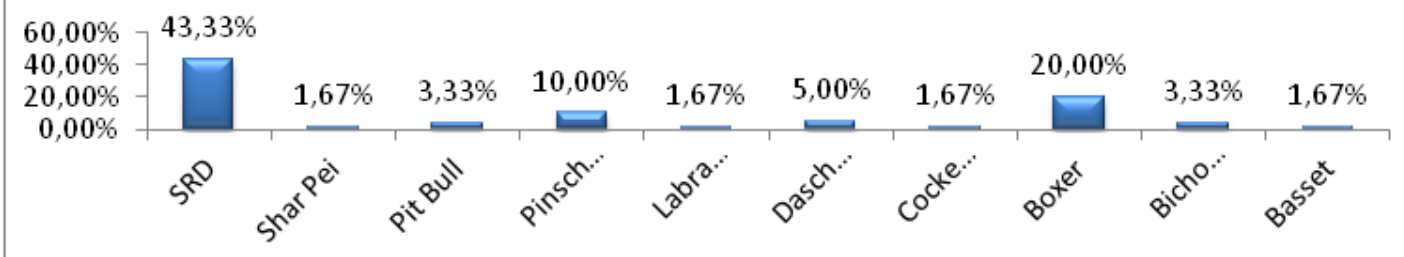

Figura 4: Frequência de mastocitomas cutâneos em cães de acordo com a raça, Uberlândia-MG, em 2013.

\section{Frequência de mastocitoma segundo a região anatômica}
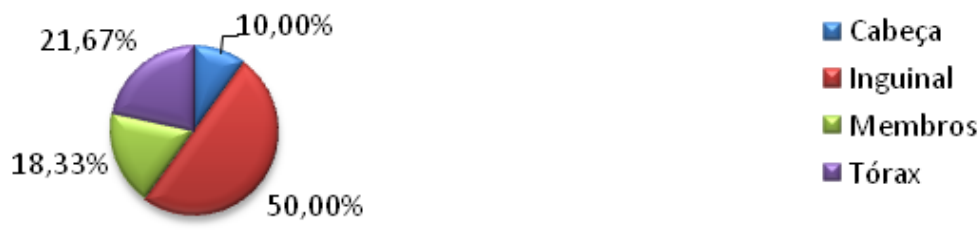

Figura 5: Frequência de mastocitomas cutâneos em cães segundo a região anatômica, Uberlândia-MG, em 2013.

Já na classificação de Kiupel et al. (2011), não houve diferença significativa entre todos os patologistas. Os patologistas 1 e 2 concordaram em todos diagnósticos $\left(x^{2}=0,000\right)$ e estes discordaram do patologista $3 \mathrm{em}$ apenas 2 diagnósticos $\left(\mathbf{X}^{2}=0,13\right)$.

Em outro estudo, Strefezzi et al. (2010) relatou que nenhum dos 23 cães avaliados foi a óbito com mastocitoma de grau I em função da neoplasia, enquanto $15,4 \%$ dos animais com mastocitoma de grau II e $83,4 \%$ dos animais de grau III tiveram suas mortes relacionadas com a doença. A sobrevida póscirúrgica dos cães analisados variou de 3 a 2.670 dias, com média de 894 dias e confirma que a avaliação histopatológica é um método seguro para avaliação e previsão da sobrevida para o mastocitoma cutâneo.

A classificação de Patnaik et al. (1984) continua sendo bastante utilizada para a avaliação do mastocitoma cutâneo por muitos

\section{Referências}

BRACARENSE, A.P.F.R.L.; PREUS, E.; MARCASSO, R.A.; REIS, A.C.F. Mastocitoma em cães estudo retrospectivo de aspectos epidemiológicos e de sobrevida. Clínica Veterinária, v. 17, n. 98, p. 84-95, 2012.

COSTA-CASAGRANDE, T.A.; ELIAS, D.S.; MELO, S.R.; MATERA, J.M. Estudo retrospectivo do mastocitoma canino no serviço de cirurgia de pequenos animais - Hospital Veterinário da Faculdade de Medicina Veterinária e Zootecnia da Universidade de São Paulo. Archives of Veterinary Science, v. 13, n. 3, p.176183, 2008. profissionais. Devido a maior chance de divergência de classificações utilizando-se esse método, a adoção do método de classificação segundo Kiupel et al. (2011) pode levar à maior reprodutibilidade dos diagnósticos. Porém, maiores estudos principalmente sobre a correlação da classificação segundo Kiupel et al. (2011) e sobrevida são necessários para validação deste método.

\section{Conclusões}

Os mastocitomas localizados na cabeça tendem a ser mais malignos do que aqueles localizados em outras regiões do corpo.

A classificação de Kiupel et al. (2011) permite maior reprodutibilidade nos resultados dos diagnósticos de mastocitomas cutâneos caninos em relação à classificação de Patnaik et al. (1984).

COUTO, C.G. Tumores de mastócitos em cães e gatos. In: NELSON R.W.; COUTO C.G. (Ed.) Medicina Interna de Pequenos Animais. 3. ed. Rio de Janeiro: Elsevier, 2006. p.1109-1111.

DALECK C.R.; ROCHA N.S.; FURLANI J.M.; CESAR J.R.F. Mastocitoma. In: DALECK C.R.; DE NARDI A.B.; RODASKI S. (Ed.) Oncologia em cães e gatos. São Paulo: Roca, 2009. p. 282-292.

DE NARDI, A.B.; RODASKI, S.; SOUSA, R.S.; COSTA, T.A.; MACEDO, T.R.; RODIGHERI, S.M.; RIOS, A.; PIEKARZ, C.H. Prevalência de neoplasias e modalidades de tratamentos em cães, atendidos no Hospital Veterinário da Universidade Federal do Paraná. Archives of Veterinary Science, v. 7, n. 2, p.15-26, 2002. 
DOBSON, J.M.; SCASE, T.J. Advances in the diagnosis and management of cutaneous mast cell tumours in dogs. Journal of Small Animal Practice, n. 48, p. 424-431, 2007.

FOX, L.E. Mast cell tumors. In: MORRISON W.B. (Ed.) Cancer in dogs and cats medical and surgical management. Philadelphia: Linppincott Williams \& Wilkins, 1998. p. 479-88.

GOLDSCHMIDTT, M.H.; SHOFER, F.S. (Ed.) Skin Tumors in the Dog and a Cat. Oxford: Pergamon Press, 1992. p. 231-251.

GOLDSCHMIDT, M.H.; HENDRICK, H.J. Tumors of the Skin and Soft Tissues. In: MEUTEN, D.J. (Ed.) Tumors in Domestic Animals. 4. ed. Lowa: lowa State Press, 2002. p. 105-107.

KIUPEL, M.; WEBSTER, J. D.; BAILEY, K. L.; BEST, S.; DeLAY, J.; ETRISAC, C.J.; FITZGERALD, S.D.;GAMBLE, D.; GINN, P.E.; GOLDSCHMIDT, M.H.;HENDRICK, M.J.; HOWERTH, E.W.; JANOVITZ, E.B.; LANGOHR, I.; LENZ, S.D.; LIPSCOMB, T.P.; MILLER, M.A.; MISDORP, W.; MOROFF, S.; MULLANEY, T.P.; NEYENS, I.; O'TOOLE, D.; RAMOS-VARA, J.; SCASE, T. J.; SCHULMAN, F.Y.; SLEDGE, D.; SMEDLEY, R.C.; SMITH, K.; SNYDER, P.W.; SOUTHORN, E.; STEDMAN, N.L.; STEFICEK, B.A.; STROMBERG, P.C.; VALLI, V.E.; WEISBRODE, S.E.; YAGER, J.; HELLER, J.; MILLER, R. Proposal of a 2-Tier histologic grading system for canine cutaneous mast cell tumors to more accurately predict biological behavior. Veterinary Pathology, Washington, v. 48, n.1, p.147-155, 2011.

MEIRELLES, A.E.W.B.; OLIVEIRA, E.C.; RODRIGUES, B.A.; COSTA, G.R.; SONNE L.; TESSER E.S.; DRIEMEIER D. Prevalência de neoplasmas cutâneos em cães da região metropolitana de Porto Alegre, RS: 1.017 casos (2002-2007). Pesquisa Veterinária Brasileira, v. 30, n. 11, p. 968-973, 2010.

NORTHRUP, N.C.; HOWERTH, E.W.; HARMON, B.G.; BROWN, C.A.; CARMICHEAL, K.P.; GARCIA, A.P.; LATIMER K.S.; MUNDAY J.S.; RAKICH P.M.; RICHEY L.J.; STEDMAN N.L.; GIEGER T.L. Uniform use of a single grading reference variation among pathologists in the histologic grading of canine cutaneous mast cell tumors with uniform use of a single grading reference. Journal of Veterinary Diagnostic Investigation, n. 17, p. 561-564, 2005.

PATNAIK, A. K.; EHLER, W. J.; MACEWEN, E. G. Canine cutaneous mast cell tumors: morphologic grading and survival time in 83 dogs. Veterinary Pathology, n. 21, p. 469-474, 1984.

PINCZOWSKI, P.; TORRES NETO, R.; FABRIS, V.E.; AMORIM, R.L. Mastocitoma cutâneo canino: variação entre observadores na graduação histopatológica. Clínica Veterinária, n. 77, p. 76-78, 2008.

PREZIOSI, R.; MORINI, M.; SARLI, G. Expression of the KIT protein (CD 117) in primary cutaneous mast cell tumors of the dog. Journal of Veterinary Diagnostic Investigation, n. 16, p. 554561,2004
RABANAL, R.; FERRER, L. (Ed.) Mast cell tumors: from the molecular biology to the clinic. In: Proceeding of the ISVD Meeting, Nice, 2002. p.11-26.

RECH, R.R. Mastócitos em condições normais e patológicas com ênfase em mastocitomas de cães. 2003. 104 f. Tese (Mestrado) Universidade Federal de Santa Maria, 2003.

SCOTT, D. W.; MILLER, W. H.; GRIFFIN, C. E. (Ed.)

Dermatologia de pequenos animais. 5. .ed. Rio de Janeiro: Interlivros, 1996. cap. 19, p. 926-1054.

SIMÕES, J.P.C.; SCHONING, P.; BUTINE, M. Prognosis of canine mast cells tumors: a comparison of threemethods. Veterinary Payhology, v. 31, n. 6, p. 637-647, 1994a.

SIMÕES, J.P.C. \& SCHONING, P. Canine mast cell tumors: a comparison of staining techniques. Journal of Veterinary Diagnostic Investigation, v. 6, p. 458-465, 1994b.

SOUZA, T.M.; FIGHERA, R.A.; IRIGOYEN, L.F.; BARROS C.S.L. Estudo retrospectivo de 761 tumores cutâneos em cães. Ciência Rural, v. 36, n. 2, p. 555-560, 2006.

STREFEZZI R.F.; XAVIER J.G.; CATÃO-DIAS J.L. Morphometry of canine cutaneous mast cell tumors. Veterinary Pathology, $\mathrm{n}$. 40 , p. 268-275, 2003

STREFEZZI R.F.; XAVIER J.G.; KLEEB S.R.; CATAO-DIAS J.L. Nuclear morphometry in cytopathology: a prognostic indicator for canine cutaneous mast cell tumors. Journal of Veterinary Diagnostic Investigation, n. 21, p. 821-825, 2009.

TAMS, T.R.; MACY, D.W. Canine mast cell tumors. Compendium of Continium Education, n. 3, p. 869-877, 1981.

TOLOSA, E. M. C.; FREITAS-NETO, A. G.; RODRIGUES, C. J.; BEHMER, O. A. Manual de técnicas para histologia normal e patológica. 2. ed. São Paulo: Manole, p. 239, 2003.

TORRES NETO, R.; PINCZOWSKI, P.; RAHAL, S.C.; KITCHELL, B.; AMORIM, R.L. Cytoplasmic and nuclear morphometric parameters in cytologic preparations of canine cutaneous mast cell tumors. Brazilian Journal of Veterinary Pathology, n. 3, p. 93-99, 2010.

TURREL, J.M.; KITCHELL, B.E.; MILLER, L.M.; THEON, A. Prognostic factors for radiation treatment of mast cell tumor in 85 dogs. Journal of the American Veterinary Medical Association, n. 193 , p. $936-940,1988$

VILLAMIL, J.A.; HENRY, C.J.; BRYAN, J.N.; ELLERSIECK, M.; SHULTZ L.; TYLER J.W.; HAHN A.W. Identification of the most common cutaneous neoplasms in dogs and evaluation of the breed and age distribuitions for selected neoplasms. Journal of the American Veterinary Medical Association, v . 239, n. 7, p. 960965, 2011. 